\title{
Feature-based attention to unconscious shapes and colors
}

\author{
FilipP SCHMIDT AND Thomas SCHMIDT \\ University of Kaiserslautern, Kaiserslautern, Germany
}

\begin{abstract}
Two experiments employed feature-based attention to modulate the impact of completely masked primes on subsequent pointing responses. Participants processed a color cue to select a pair of possible pointing targets out of multiple targets on the basis of their color, and then pointed to the one of those two targets with a prespecified shape. All target pairs were preceded by prime pairs triggering either the correct or the opposite response. The time interval between cue and primes was varied to modulate the time course of feature-based attentional selection. In a second experiment, the roles of color and shape were switched. Pointing trajectories showed large priming effects that were amplified by feature-based attention, indicating that attention modulated the earliest phases of motor output. Priming effects as well as their attentional modulation occurred even though participants remained unable to identify the primes, indicating distinct processes underlying visual awareness, attention, and response control.
\end{abstract}

Early theories of visual attention and visual awareness hypothesized a close connection between both processes: Only objects we attend to should reach awareness (James, 1890; cf. Merikle \& Joordens, 1997; O'Regan \& Noë, 2001; Posner, 1994). However, recent studies suggest that visual attention and awareness are distinguishable and depend on different neurophysiological processes (Dehaene, Changeux, Naccache, Sackur, \& Sergent, 2006; Koch \& Tsuchiya, 2007; Lamme, 2003, 2005). In particular, several studies have shown effects of space-based attention on stimuli that do not reach visual awareness (e.g., Kentridge, Nijboer, \& Heywood, 2008; Melcher, Papathomas, \& Vidnyánszky, 2005; Sumner, Tsai, Yu, \& Nachev, 2006; Zhaoping, 2008). Recently, Shin, Stolte, and Chong (2009) demonstrated attentional effects on contrast thresholds for the detection of grating stimuli and on thresholds for the discrimination of gender in faces, for stimuli rendered invisible by binocular rivalry.

A further development in visual attention research is the growing interest in attentional processes based on visual features (such as color, shape, or motion direction) instead of spatial position. It has been shown that when macaque monkeys attend to the direction of a moving texture, feature-based attention modulates throughout the visual field the responses of neurons selective for that motion direction (Treue \& Martínez-Trujillo, 1999). Effects of feature-based attention have also been demonstrated in numerous other psychophysical, imaging, and single-unit studies using motion as well as color or shape stimuli (e.g., Corbetta, Miezin, Dobmeyer, Shulman, \& Petersen, 1990; Martínez-Trujillo \& Treue, 2004; Mounts
\& Melara, 1999; O'Craven, Rosen, Kwong, Treisman, \& Savoy, 1997; Sàenz, Buracas, \& Boynton, 2002, 2003; Serences \& Boynton, 2007; Tapia, Breitmeyer, \& Shooner, 2010; for a review, see Maunsell \& Treue, 2006).

But can feature-based attention also be dissociated from visual awareness? Kanai, Tsuchiya, and Verstraten (2006) employed continuous flash suppression where an adaptation stimulus is rendered invisible by presenting rapidly changing masking patterns to the other eye. They demonstrated that the invisible adaptation stimulus (a bar slightly tilted from the vertical axis) was still able to induce a tilt aftereffect (the perception of opposite tilt in a subsequently presented, truly vertical stimulus). Adaptation to invisible stimuli was modulated by feature-based attention, with stimulus orientation as the relevant feature. Note, however, that tilt adaptation is a slow-acting process, working in a time range of seconds or minutes. What is still lacking is a paradigm able to trace the time course of feature-based attention in ongoing, speeded visuomotor processing.

In the domain of space-based attention, such a paradigm was devised by Schmidt and Seydell (2008). They employed a response priming paradigm (Neumann \& Klotz, 1994; Vorberg, Mattler, Heinecke, Schmidt, \& Schwarzbach, 2003), where the target stimulus of a pointing response is preceded by a visually masked prime stimulus affording a response to the same or the opposite direction (Schmidt, 2002). This results in a response priming effect, where the pointing response to the target is speeded when the prime triggers a response consistent with the target, and delayed or misdirected when it triggers the opposite response (Schmidt, 2002; Schmidt, Niehaus, \&

F. Schmidt, filipp.schmidt@sowi.uni-kl.de 
Nagel, 2006; Schmidt \& Schmidt, 2009). These priming effects increase monotonically with the stimulus onset asynchrony (SOA) between prime and target. Schmidt and Seydell (2008) demonstrated that space-based attention boosted priming effects in ongoing speeded pointing movements, such that primes at attended positions had a larger effect on pointing responses to subsequent targets when attention was summoned to their positions by endogenous or exogenous spatial cues.

The authors did not, however, explicitly investigate the degree of visual masking of the primes. But, in fact, one striking property of response priming is its independence from visibility of the prime: The early time course of priming is invariant, whether primes are visible or invisible, and can even run opposite to the time course of visual awareness of the prime (Vorberg et al., 2003; see also Mattler, 2003; Schmidt \& Vorberg, 2006). In the present article, we demonstrate that visual awareness of the prime can be dissociated from two types of processes: First, from response priming in ongoing pointing movements, and second, from attentional modulation of those priming effects. We thus show that visual attention can modulate the temporal dynamics of primed pointing responses, even though the primes remain invisible, demonstrating a threefold dissociation of priming, attention, and awareness.

\section{EXPERIMENT 1}

We studied the impact of feature-based attention on priming by presenting a circular configuration of 10 possible targets (squares and circles) preceded by 10 primes at the same positions (Schmidt \& Seydell, 2008). Stimuli occurred in five different colors, such that each pair of opposite stimuli would consist of one circle and one square in the same color (Figure 1). They were visually masked by the subsequent targets (metacontrast masking; Breitmeyer \& Öğmen, 2006). To know which of the target pairs to respond to, participants had to process a color cue, presented before prime onset, that indicated the relevant pair of opposite targets. The amount of attentional preparation was controlled by varying the time interval between cue and prime onset (cuing interval). Once the relevant color pair had been identified, the task was to point as quickly as possible to the circle-shaped target of that pair. Primes were either all consistent to the targets (such that prime and target shapes coincided at each position) or all inconsistent to the targets (such that prime shapes were switched when compared with target shapes).

The advantage of this design is that, prior to attentional selection, primes as well as targets should have a spatially neutral impact on the motor response, because they are distributed evenly around the starting point. Upon pro-
Cue

$50 \mathrm{msec}$
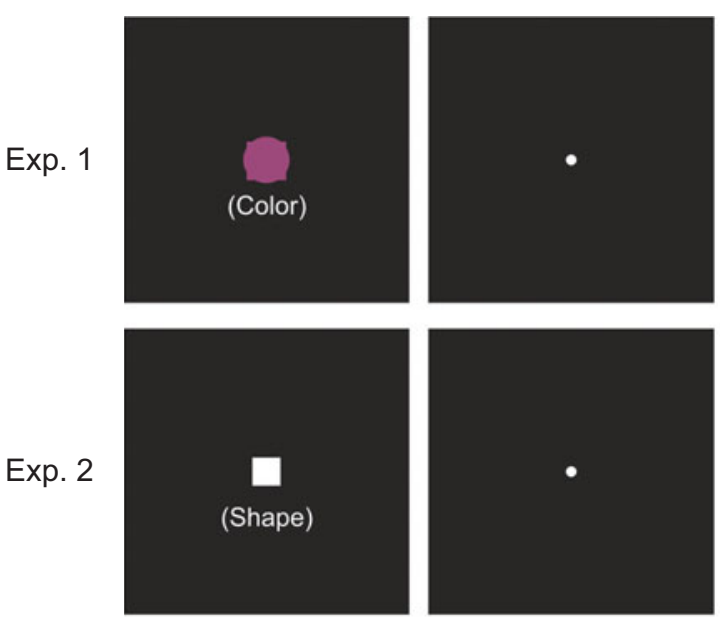

Primes

$17 \mathrm{msec}$
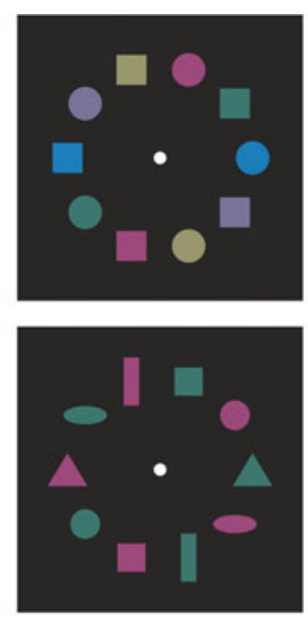

Targets (until response)
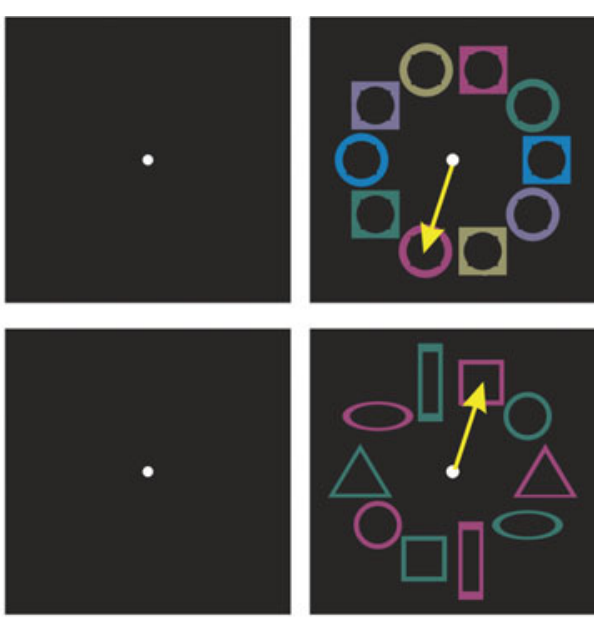

Prime-Target SOA

$(33,67,100 \mathrm{msec})$
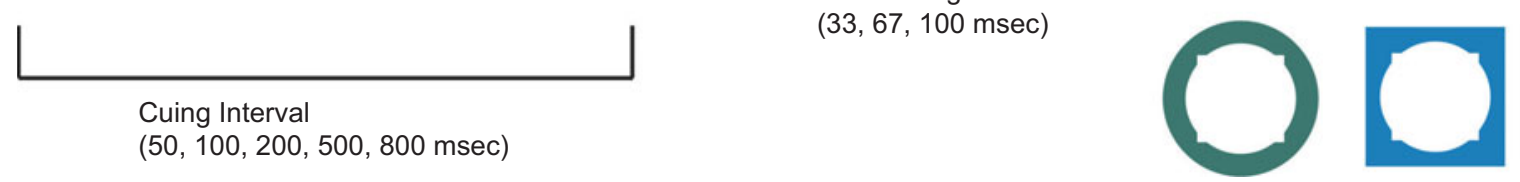

Figure 1. Stimuli and procedure. Ten primes and 10 targets were presented in the sequence displayed; the arrow symbolizes the stylus movement from the starting position on the fixation point toward the correct target stimulus. Upper panel: In Experiment 1, colors were yellow, red, green, blue, and violet, with pairs of opposite stimuli always sharing the same color. The correct target was defined as the circle appearing in the color of the cue. Targets were designed to mask both circle-shaped and square-shaped primes. Lower panel: In Experiment 2, colors were red and green, with opposite stimuli always different in color. The correct target was defined as the red one appearing in the shape of the cue. 
cessing of the cue, visual attention should start to select the relevant feature indicated by the cue, and thus allow upcoming primes with that feature to have a spatially directional effect on the pointing movement. One consequence of this arrangement is that visual (feature-based) selection is necessary for performing the task in the first place ("selection for action"; Allport, 1989). A second consequence is that attention enables spatially directed priming effects, which could not occur in the absence of attentional selection. In turn, any observation of spatially directed priming effects (e.g., deflections of the pointing trajectories toward a cued prime) implies that featurebased selection must have taken place. At the same time, any modulation of these priming effects by cuing interval would indicate different degrees of attentional selection. ${ }^{1}$

\section{Method}

Participants. Eight right-handed students from the University of Giessen, Germany (5 women and 3 men; age range, 21-29 years), with normal or corrected-to-normal vision, participated in the experiment for payment of $€ 8 / \mathrm{h}$ or course credits. Participants were debriefed after the final session and received an explanation of the experiment. All of them gave informed consent and were treated in accordance with the ethical guidelines of the American Psychological Association.

Apparatus and Stimuli. The monitor image was projected onto a workspace via a set of two mirrors, so that the participants had the impression that the stimuli appeared directly on the workspace where they could interact with them. The workspace was tilted toward the participant at a $60^{\circ}$ angle out of the transverse plane at a viewing distance of approximately $70 \mathrm{~cm}$. Pointing responses were recorded by a Polhemus FASTRAK magnetic tracking device at a sampling frequency of $120 \mathrm{~Hz}$. The sensor was referenced to the tip of a handheld stylus, and the workspace was illuminated so that participants could view the hand and stylus superimposed on the stimuli.

Primes were small disks $\left(1.091^{\circ}\right.$ of visual angle; $1 \mathrm{~mm} \approx 0.082^{\circ}$ of visual angle) and squares $\left(0.975^{\circ}\right)$ presented against a dark background $\left(0.07 \mathrm{~cd} / \mathrm{m}^{2}\right)$. Targets were annuli and hollow squares, with outer diameters of $1.560^{\circ}$ and $1.364^{\circ}$, respectively. The inner cutouts of the targets had the shape and size of a circular and a square prime superimposed to allow for metacontrast masking of both shapes. The fixation point $\left(83.00 \mathrm{~cd} / \mathrm{m}^{2}\right)$ in the center of the screen had a diameter of $0.117^{\circ}$. The 10 prime and target stimuli were spaced equally around the fixation point at regular intervals at a distance of $4.675^{\circ}$. Psychometric isoluminance of all five stimulus colors was ascertained by heterochromatic flicker photometry carried out with 3 independent observers. The resulting colors were desaturated yellow, red, green, blue, and violet, with luminances between 13.20 and $16.50 \mathrm{~cd} / \mathrm{m}^{2}$.

Procedure. Each trial started with the appearance of the central fixation point. The participants placed a handheld pointing stylus on the fixation point and started the trial by pressing the space bar. After a variable delay, the cue was presented for $50 \mathrm{msec}$ in the center of the screen. Following a cuing interval (time from cue onset) of $50,100,200,500$, or $800 \mathrm{msec}$, the 10 primes were presented for $17 \mathrm{msec}$. Finally, the 10 targets were presented at prime-target SOAs of either 33,67 , or $100 \mathrm{msec}$, and remained on screen until participants had finished the response. The time interval from fixation onset to target onset was constant at $1,000 \mathrm{msec}$, to allow for optimal preparation for response to the target. Prime shapes were either all consistent or all inconsistent to target shapes. All stimulus combinations of consistency, cuing interval, prime-target SOA, cue color, and correct target position occurred equiprobably and pseudorandomly in a completely crossed repeated measures design.

We employed two tasks: a speeded target identification task (target ID, designed to measure response priming) and a prime identi- fication task ( prime ID, designed to measure visual awareness of the primes). In target ID, participants pointed as quickly as possible to the circle-shaped target in the color of the cue. Responses were registered when the stylus sensor entered a $30-\mathrm{mm}$ radius around any target location; summary feedback on response times (RTs) and error rates was provided after each block. In prime ID, participants pressed a key depending on whether they believed that the circleshaped prime in the cued color had been presented in the left or right half of the display (without any time pressure). ${ }^{2}$ Note that both tasks were two-alternative forced choice (2AFC) tasks (Macmillan \& Creelman, 2005), because participants had to consider the two response-relevant locations only (i.e., those two positions where stimuli in the cued color could appear). Furthermore, both tasks employed the same stimuli and cuing procedure, and we took care that the prime-ID task would focus on exactly the stimulus information (i.e., prime shape) that would drive the priming effect in the targetID task (Schmidt \& Vorberg, 2006).

In prime ID, only the longest cuing interval $(800 \mathrm{msec})$ was employed. Participants performed six 1-h sessions of target ID, followed by two 1-h sessions of prime ID, each consisting of 1 practice block followed by 30 blocks of 30 trials. Participants were informed about the presence and the nature of the primes prior to the prime-ID sessions.

Data treatment and statistical methods. Practice blocks were not analyzed. Trials in target ID were eliminated if the participant had hit one of the uncued target locations (thus missing both the correct and the opposite target), or if arrival times were shorter than $100 \mathrm{msec}$ or longer than $999 \mathrm{msec}$. Responses were thus classified as true errors only if the target location opposite the correct one was hit. In prime ID, only trials with RTs exceeding a timeout criterion of $15 \mathrm{sec}$ were excluded. These criteria eliminated $5.37 \%$ of trials in target ID, and no trials in prime ID.

In target ID, the entire time course of pointing trajectories was analyzed, specifically looking at the spatial position of the stylus sensor as a function of time. Pointing trajectories were simplified by projecting them onto a line connecting the circle-shaped and square-shaped target at the response-relevant positions. The starting point was defined as zero and the correct target direction as positive. Additionally, trajectorial priming functions were established as a spatiotemporal measure of priming by subtracting average pointing trajectories in consistent trials from those in inconsistent trials. Negative values of this function indicate that the sensor position in inconsistent trials lags behind the sensor position in consistent trials at corresponding points in time.

Kinematic parameters of pointing trajectories and trajectorial priming functions were extracted by jackknifing methods (Ulrich \& Miller, 2001). ${ }^{3}$ Repeated measures ANOVAs were performed with Greenhouse-Geisser-corrected $p$ values. All ANOVAs were fully factorial, with factors of cuing interval (I), prime-target SOA (S), and consistency $(\mathrm{C})$. We report $F$ values with subscripts indicating the respective effect (e.g., $F_{1 \times \mathrm{S}}$ for the interaction of cuing interval and prime-target SOA). Error rates were arcsine transformed to make them compatible with ANOVA requirements. Only significant results are reported here.

\section{Results and Discussion}

Target ID. Pointing and priming onsets were exactly time-locked to prime onset, starting at a fixed time following prime onset, even though participants were supposed to respond to the targets. On average, responses initially went into the direction specified by the primes, particularly at long prime-target SOAs (Figure 2, left panels). When primes and targets were consistent, this initial direction was correct, and the sensor simply traveled toward the correct target until the response was completed. When primes and targets were inconsistent, however, the sensor initially traveled into the quadrant occupied by the 


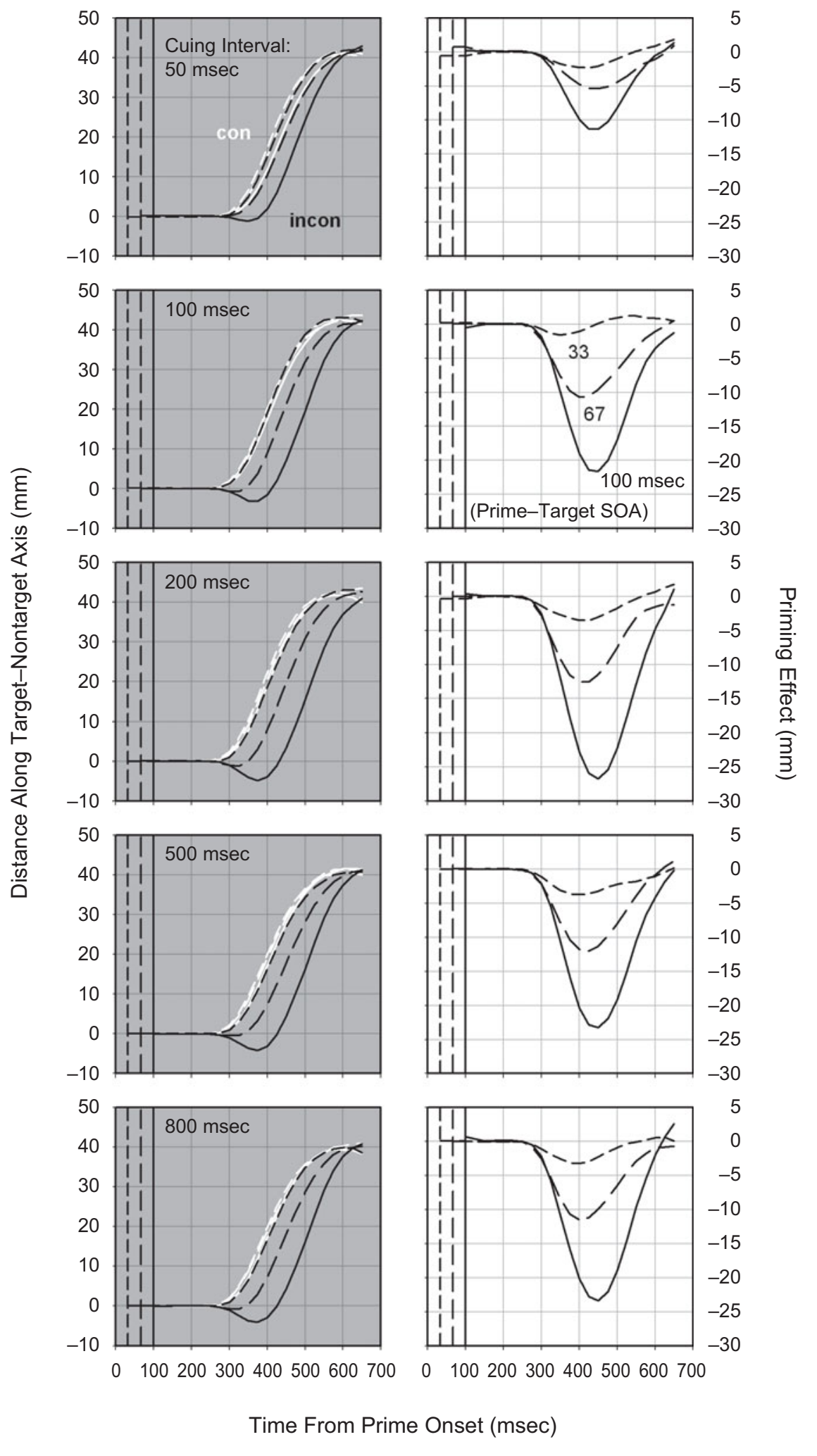

Figure 2. Pointing trajectories in Experiment 1. Left panels: Positions of the stylus projected onto the imaginary axis between correct and opposite target, plotted separately for the different cuing intervals. Positive values indicate movement toward the correct target. The time axis is locked to prime onset; vertical lines denote the times of target onset for the different prime-target SOAs. Trajectories are shown in white for consistent trials, and in black for inconsistent trials, with dashing indicating prime-target SOA. Right panels: Trajectorial priming functions, defined as the difference between average consistent and inconsistent pointing trajectories. Negative values indicate that the stylus position in inconsistent trials lags behind the stylus position in consistent trials at corresponding points in time. 
misleading prime. Then the pointing movement was redirected into the correct direction unless participants had produced an actual error (i.e., arrival at the target position opposite the correct one). The duration and spatial extent of such a detour into the wrong quadrant increased with prime-target SOA. These basic results are in line with previous findings (Schmidt, 2002; Schmidt et al., 2006; Schmidt \& Schmidt, 2009; Schmidt \& Seydell, 2008).

Detours into the wrong quadrant occurred only in a minority of trials - namely those with particularly fast response onsets (Figure 3). In those fast-onset trials, responses were as likely to start in the correct as in the incorrect direction, depending only on prime instead of target direction. In the remaining trials, priming effects manifested in a delay in pointing onset in inconsistent trials relative to consistent trials (Schmidt et al., 2006). The fact that priming effects were always clearly time-locked to prime instead of target onset suggests that the underlying response conflicts were similar in responses with delayed onset and those with overt detours.

Priming effects were quantified in the temporal and spatial domain. Effects in the temporal domain were calculated by setting two spatial criteria and evaluating the point in time when the unfolding movement crossed these boundaries (early criterion, $3.0 \mathrm{~mm}$ from fixation in the correct direction; arrival criterion, $18-\mathrm{mm}$ radius around correct target; temporal priming effects are defined as the difference in crossing times in inconsistent minus consistent trials). ${ }^{4}$ Both early and arrival criteria were crossed later in inconsistent than in consistent trials $\left[F_{\mathrm{C}}(1,7)=35.59\right.$ and 69.13 , respectively, both $\left.p \mathrm{~s}<.001\right]$. These priming effects increased strongly with increases in prime-target SOA $\left[F_{\mathrm{C} \times \mathrm{S}}(2,14)=32.54\right.$ and 6.03 , $p<.001$ and $p=.036$, respectively], reaching values of $100 \mathrm{msec}$ and more. Priming effects increased with cuing interval in onset times only $\left[F_{\mathrm{C} \times \mathrm{I}}(4,28)=8.59, p=.001\right]$; the arrival criterion revealed a small decrease in priming for cuing intervals longer than $200 \mathrm{msec}$. Crossing times also increased with increases in prime-target SOA alone at both criteria $\left[F_{\mathrm{S}}(2,14)=98.27\right.$ and 16.82 , both $p \mathrm{~s}<$ $.001]$, primarily due to increasing crossing times in inconsistent trials (Figures 4A and 4B). Response errors (actual arrivals at the position opposite the correct target) showed a similar pattern: Errors were made almost exclusively in inconsistent trials $\left[F_{\mathrm{C}}(1,7)=10.58, p=.014\right]$ and, there, increased strongly with increases in prime-target SOA $\left[F_{\mathrm{C} \times \mathrm{S}}(2,14)=11.13, p=.008\right]$ and cuing interval $\left[F_{\mathrm{C} \times \mathrm{I}}(4,28)=4.87, p=.012\right]$. Additionally, both intervals had an effect on the error rate by themselves, with increasing error rates for longer cuing intervals and primetarget SOAs $\left[F_{1}(4,28)=8.33, p<.001\right.$, and $F_{\mathrm{S}}(2,14)=$ $12.73, p=.006$, respectively]; see Figure 4C. Importantly, the occurrence of detours and errors shows that featurebased selection of the response-relevant positions must have taken place prior to movement onset, because primes as well as targets were spatially neutral in their impact on the pointing movements unless color-based selection had taken place.

Prime-target SOA and cuing interval affected all phases of the pointing response, including the onset of the spatial priming effect and the peak priming amplitude. The onsets of priming effects were determined by calculating the moment (from prime onset) when the trajectorial priming function first fell below $-0.5 \mathrm{~mm}$ (meaning that the sensor position in inconsistent trials lagged at least $0.5 \mathrm{~mm}$ behind that in consistent trials). With increasing cuing interval, these onset times became shorter $\left[F_{1}(4,28)=4.23\right.$, $p=.035]$, whereas prime-target SOA had no systematic influence on priming onset (Figure 5A).

If the onset of the spatial priming effect is indeed locked to prime onset, a regression of priming onset on target onset should yield a slope of -1 ; that is, priming onsets calculated with respect to target onset should be staggered by exactly the prime-target SOA. Importantly, for all cuing intervals, priming onsets depended linearly on target onset with slopes of $-1.17 \leq b \leq-1.00$ [all $F_{\mathrm{s}}(1,22) \geq 6.33$, all $p \mathrm{~s} \leq .020$, all $\left.R^{2} \mathrm{~s} \geq .93\right]$. Slopes were not significantly different from the slope of -1 that would be predicted if onsets were in fact time-locked to the prime [all $\left.F_{\mathrm{s}}(1,22)<1\right]$.

The peak priming amplitude was defined as the maximal negative value (in millimeters) achieved by the trajectorial priming function. Peak amplitude was significantly different from zero $\left[F_{\text {intercept }}(1,7)=27.40, p=.001\right]$ at all prime-target SOAs [all $F_{\mathrm{s}}(1,7) \geq 17.76$, all $p \mathrm{~s}<$ $.005]$. It strongly increased with increases in prime-target SOA $\left[F_{\mathrm{S}}(2,14)=24.67, p=.001\right]$ and cuing interval $\left[F_{1}(4,28)=19.88, p<.001\right]$. Moreover, the interaction between cuing interval and prime-target SOA reached significance $\left[F_{1 \times S}(8,56)=9.51, p<.001\right]$, indicating that priming effects increased more steeply with prime-target SOA at longer cuing intervals (Figure 5B). This modulation of early-response dynamics indicates an influence of attention on visuomotor processes prior to pointing onset. Importantly, the modulation by cuing interval indicates that at least some selection processes must take place on the basis of features, not locations, because no information about the relevant prime locations is available during the cuing interval. In sum, it seems that the more efficiently attention was directed to a certain feature, the more it enhanced visuomotor processing of upcoming stimuli that contained that feature, thereby amplifying the effects of the respective primes.

Prime ID. Identifiability of masked primes was examined in a $2 \mathrm{AFC}$ task for all of the three prime-target SOAs but only one cuing interval $(800 \mathrm{msec}$, the one expected to be optimal for prime identification performance). Participants' ability to report whether the circle prime in the cued color was in the left or right half of the display was essentially at chance. Correct identification performance reached values of $50.05 \%, 50.72 \%$, and $51.56 \%$ at prime-target SOAs of 33, 67, and $100 \mathrm{msec}$, respectively, a variation too small to account for the large differences in priming amplitude (Figure 10, left panel); $\chi^{2}$ tests on crosstables of hits, false alarms, misses, and correct rejections conducted for each participant, and SOA revealed that out of the 24 tests, only 3 became significant. ${ }^{5}$ One participant reached accuracies of $56.60 \%$ and $62.33 \%$ at prime-target SOAs of 67 and $100 \mathrm{msec}$, respectively (both $p$ s $\leq .002$ ), and another participant reached an accuracy of $54.50 \%$ at 


\section{Direction:}
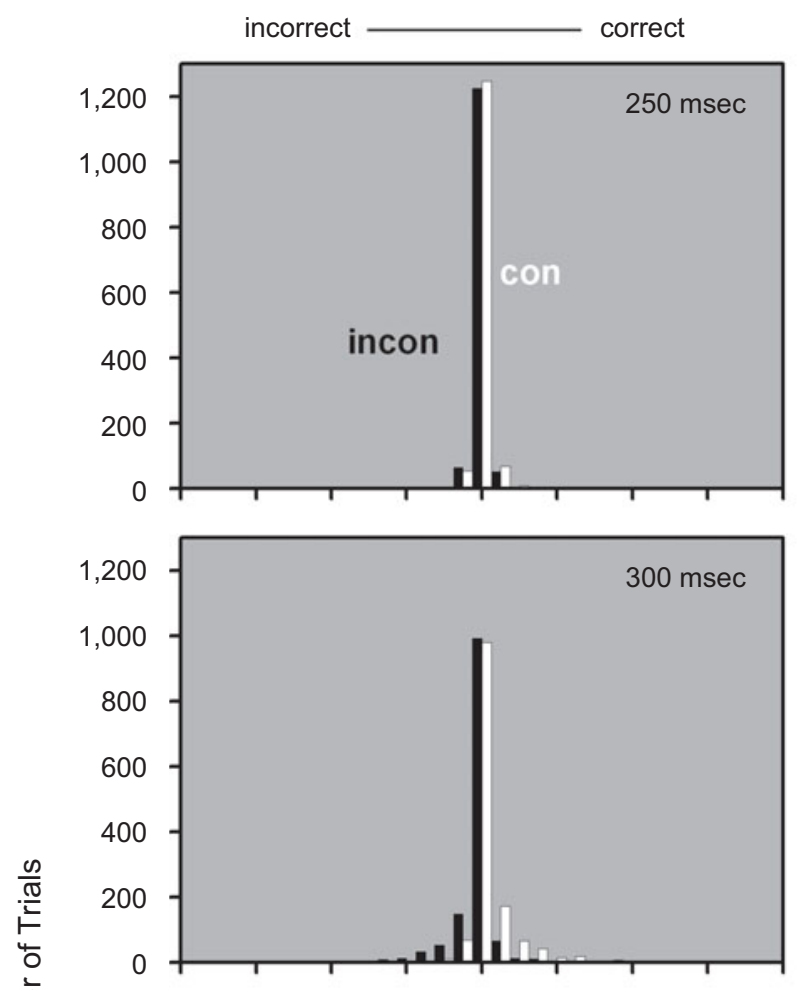

ํํำ
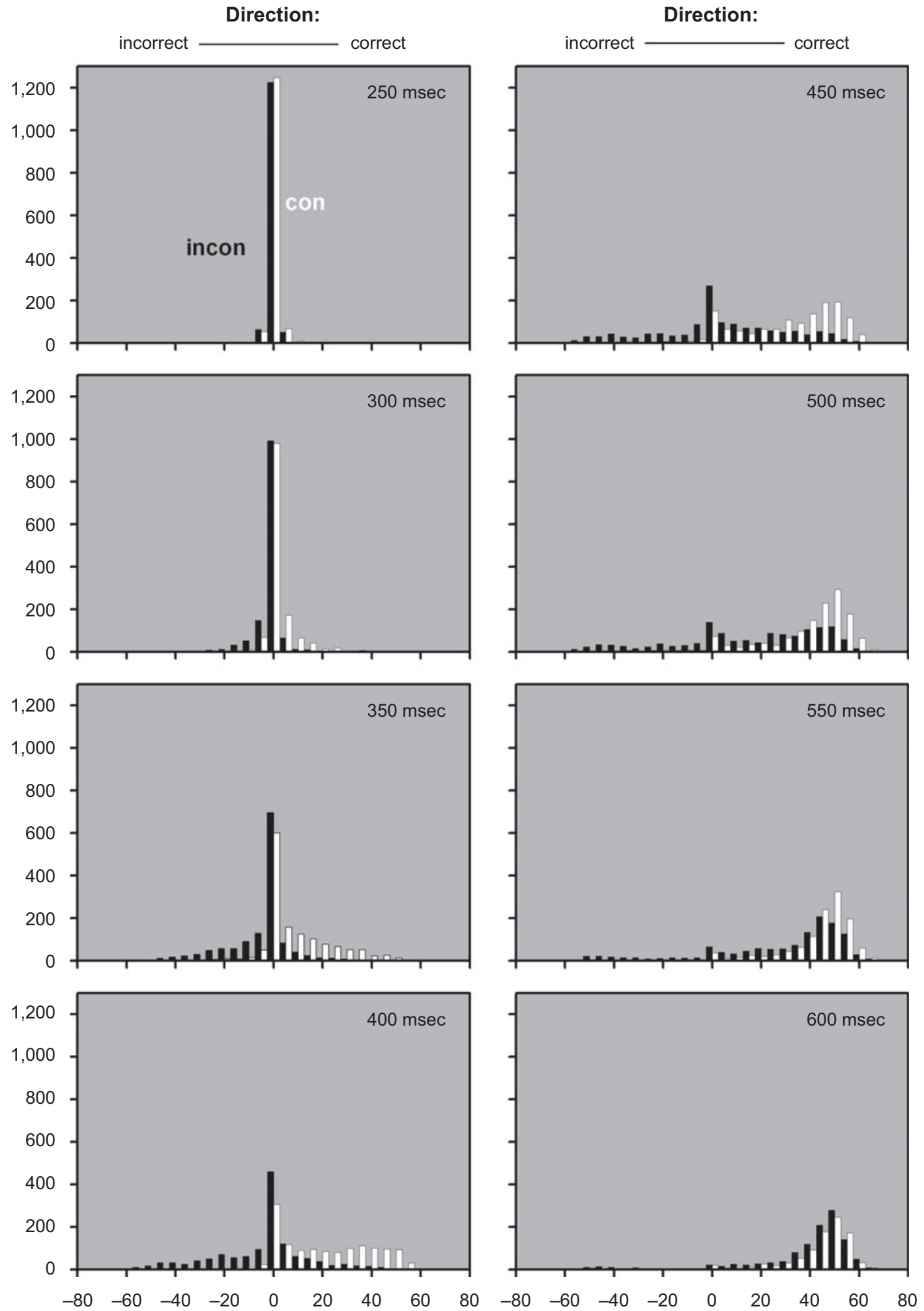

Finger Position Along Target-Nontarget Axis (mm)

Figure 3. Spatial distributions of finger positions in Experiment 1 at different times after prime onset for consistent (white bars) and inconsistent (black bars) trials. Data are from the condition producing the largest priming effects (cuing interval $200 \mathrm{msec}$, prime-target SOA $100 \mathrm{msec}$ ) and include correct as well as incorrect responses. Each panel shows the distribution of positions in a 50-msec interval centered on the denoted value. Finger positions are binned into 5-mm intervals. Trajectories are normalized so that the direction of the correct target is plotted rightward. Distributions are based on the projections of finger positions onto the line connecting the correct target with the incorrect one. 

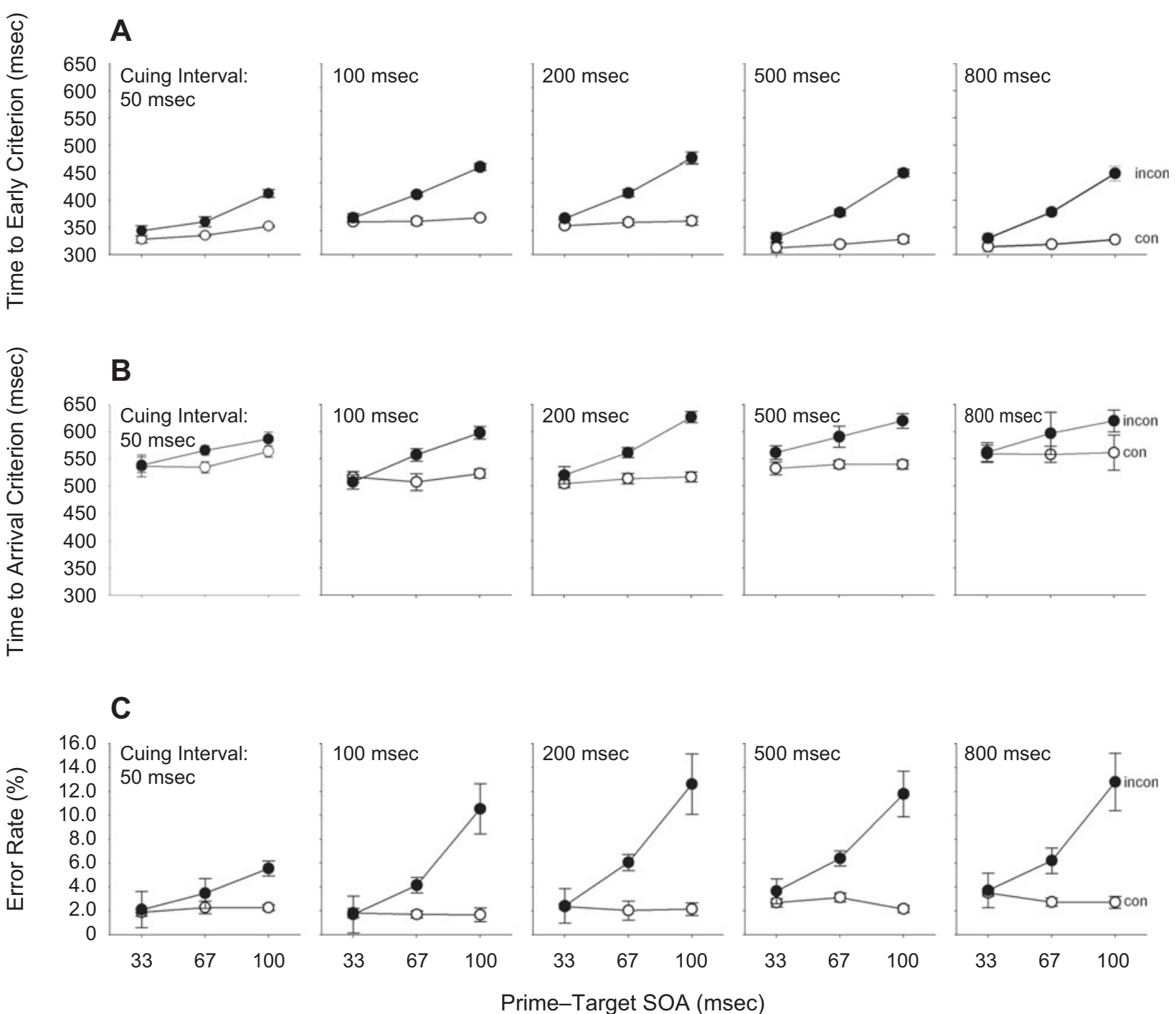

Prime-Target SOA (msec)

Figure 4. Parameters of pointing trajectories in Experiment 1 as a function of prime-target SOA: (A) Time to an early criterion, (B) time to arrival criterion, and (C) error rates in consistent (white) and inconsistent (black) trials. Error bars denote the standard error of the mean estimated from jackknifed data (Ulrich \& Miller, 2001), corrected for between-subjects variance (Bakeman \& McArthur, 1996; Loftus \& Masson, 1994).

the 67 -msec SOA $(p=.011)$. However, priming effects of these 2 participants did not differ from those of the remaining participants. In sum, visual awareness of the primes can be regarded as effectively dissociated from both response priming and attentional selection of the primes.

\section{EXPERIMENT 2}

In Experiment 2, the roles of color and shape were exchanged. Accordingly, shape was now the guiding feature for feature-based attention, and participants thus had to point to the stimulus of prespecified color in the shape of the cue.

\section{Method}

Participants. Eight right-handed students from the University of Giessen, Germany (all women; age range, 22-32 years), with normal or corrected-to-normal vision, participated in the experiment for payment of $€ 8 / \mathrm{h}$ or course credits. Participants were debriefed after the final session and received an explanation of the experiment. All of them gave informed consent and were treated in accordance with the ethical guidelines of the American Psychological Association.

Apparatus and Stimuli. The apparatus, data treatment, and statistical methods were equivalent to those in Experiment 1. The primes were small circles (diameter $1.170^{\circ}$ of visual angle), squares $\left(0.936^{\circ}\right)$, rectangles $\left(1.247^{\circ} \times 0.624^{\circ}\right)$, ellipses (major axis $1.560^{\circ}$, minor axis $0.780^{\circ}$ ), and isosceles triangles (base and height $1.247^{\circ}$ ), presented against a dark background $\left(0.07 \mathrm{~cd} / \mathrm{m}^{2}\right)$. The target stimuli were hollow shapes, circles $\left(1.637^{\circ}\right.$ diameter $)$, squares $\left(1.403^{\circ}\right)$, rectangles $\left(1.871^{\circ} \times 0.936^{\circ}\right)$, ellipses (major axis $2.183^{\circ}$, minor axis $1.091^{\circ}$ ), and isosceles triangles (base and height $1.871^{\circ}$ ), with their inner cutouts exactly the size of the primes. Cue stimuli (white, $83.0 \mathrm{~cd} / \mathrm{m}^{2}$ ) had the same dimensions as the primes. In each display, primes and targets appeared alternately in red and green (color specifications taken from Experiment 1), so a green prime (or target) would always be opposite a red one.

Procedure. The procedure was identical to Experiment 1, except for the roles of color and shape. Primes now appeared in the same 
A

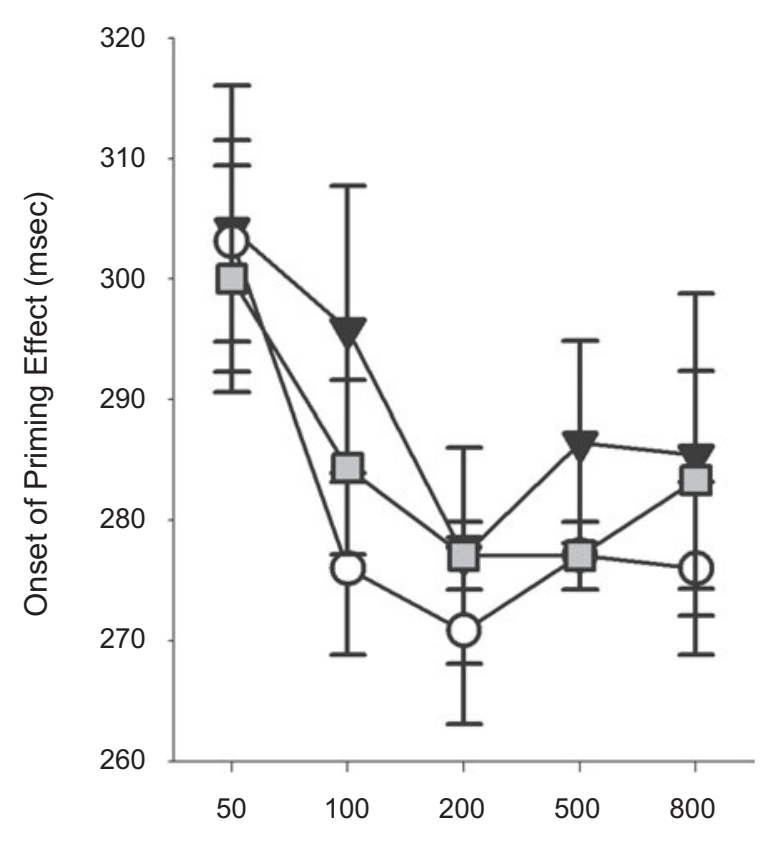

B

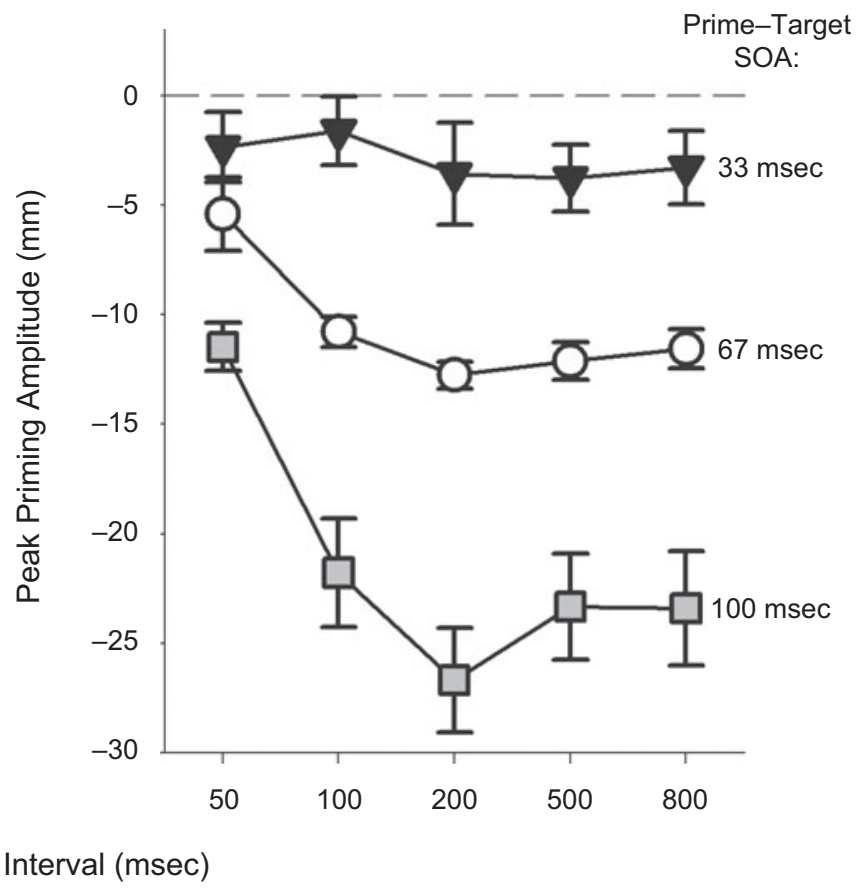

Figure 5. Parameters of priming trajectories in Experiment 1 as a function of cuing interval: (A) Onset of the priming effect; (B) peak priming amplitude for short ( $33 \mathrm{msec}$; black triangles), middle (67 msec; white circles), and long (100 msec; gray rectangles) prime-target SOAs.

shapes as the targets, but their colors were either all consistent or all inconsistent to target colors (Figure 1). In target ID, participants pointed as quickly as possible from display center to the red target in the shape of the cue; summary feedback on RTs and error rates was provided after each block. In prime ID, participants tried to detect the position of the red prime in the shape of the cue. In a manner different from the prime-ID task in Experiment 1, participants now had to point directly toward the prime, and all cuing intervals were included. Therefore, the prime-ID task was no longer a symbolic keypress decision, which might arguably underestimate sensitivity, but strictly comparable to the target-ID task (Schmidt \& Vorberg, 2006). Again, note that both tasks were $2 \mathrm{AFC}$ tasks because participants had to consider the two response-relevant locations only. Participants performed six 1-h sessions of target ID, followed by two 1-h sessions of prime ID, each consisting of one practice block followed by 30 blocks of 30 trials.

Data treatment. Practice blocks were not analyzed. Trials in target ID were eliminated if the participant had hit one of the uncued target locations, or if arrival times were shorter than $100 \mathrm{msec}$ or longer than 1,299 $\mathrm{msec}$ (the new exclusion criterion was chosen because responses were altogether slower than in Experiment 1). Trials in prime ID were eliminated if the participant had hit one of the uncued target locations, or if RTs exceeded a timeout criterion of $15 \mathrm{sec}$. These criteria eliminated $5.56 \%$ of trials in target ID and $5.00 \%$ of trials in prime ID.

\section{Results and Discussion}

Target ID. After the occurrence of primes and targets, the pointing stylus remained at fixation for roughly $350 \mathrm{msec}$ (Figure 6, left panels), about $70 \mathrm{msec}$ longer than in Experiment 1. In consistent trials, the sensor then moved continuously and straightly from fixation toward the relevant target until arrival. In inconsistent trials, how- ever, pointing onset was delayed, and the delay was more pronounced the more time had elapsed between prime and target onset. In contrast to Experiment 1, there were virtually no overt detours toward the misleading prime (Figure 7).

As in Experiment 1, both the early criterion and the arrival criterion (now defined as a radius of $23 \mathrm{~mm}$ around the correct target position) were crossed earlier in consistent trials than in inconsistent trials $\left[F_{\mathrm{C}}(1,7)=260.59\right.$ and 134.49 , both $p$ s $<.001]$. These priming effects increased strongly with increases in prime-target SOA $\left[F_{\mathrm{C} \times \mathrm{S}}(2,14)=24.60\right.$ and 15.30 , both $\left.p \mathrm{~s}<.001\right]$, reaching values of about $80 \mathrm{msec}$. Again, priming effects increased with cuing interval $\left[F_{\mathrm{C} \times \mathrm{I}}(4,28)=6.48\right.$ and $7.09, p=.014$ and .005 , respectively]. Overall, crossing times increased with increases in prime-target SOA $\left[F_{\mathrm{S}}(2,14)=195.65\right.$ and 30.37 , both $p \mathrm{~s}<.001]$ (see Figures $8 \mathrm{~A}$ and $8 \mathrm{~B}$ ). Response errors showed a similar pattern: As in Experiment 1, errors were made almost exclusively in inconsistent trials and, there, increased with increases in primetarget SOA and cuing interval. However, because error rates were very low in all conditions with an overall mean of only $0.29 \%$, no effects of cuing interval or prime-target SOA reached significance (see Figure 8C).

Again, prime-target SOA and cuing interval affected all phases of the pointing response, including the onset of the spatial priming effect and its peak amplitude. The onset times of the spatial priming effect (defined as the time when the trajectorial priming function first fell below $-0.5 \mathrm{~mm}$ ) became shorter with increasing cuing inter- 


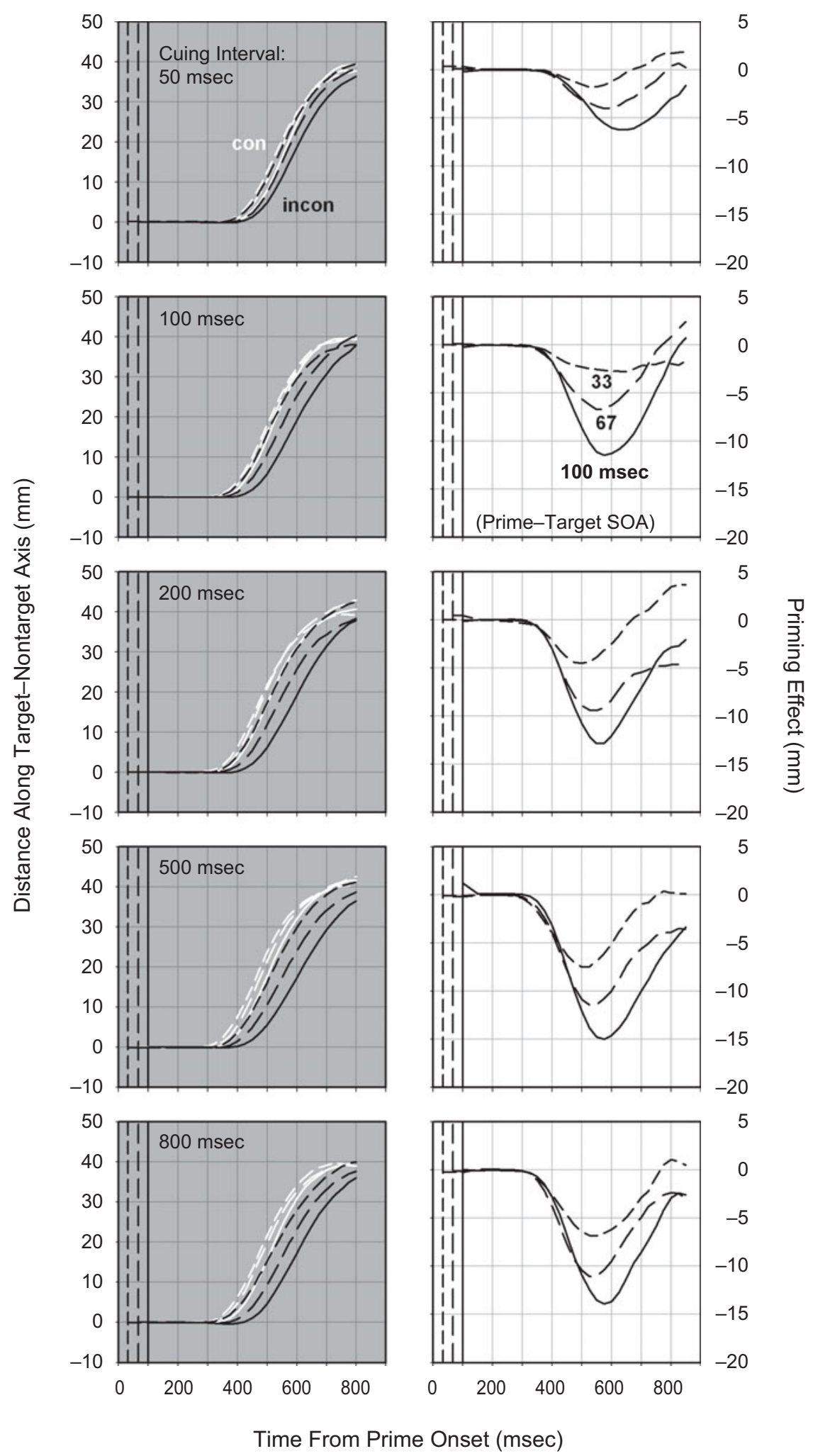

Figure 6. Pointing trajectories in Experiment 2. Conventions are the same as in Figure 2. 


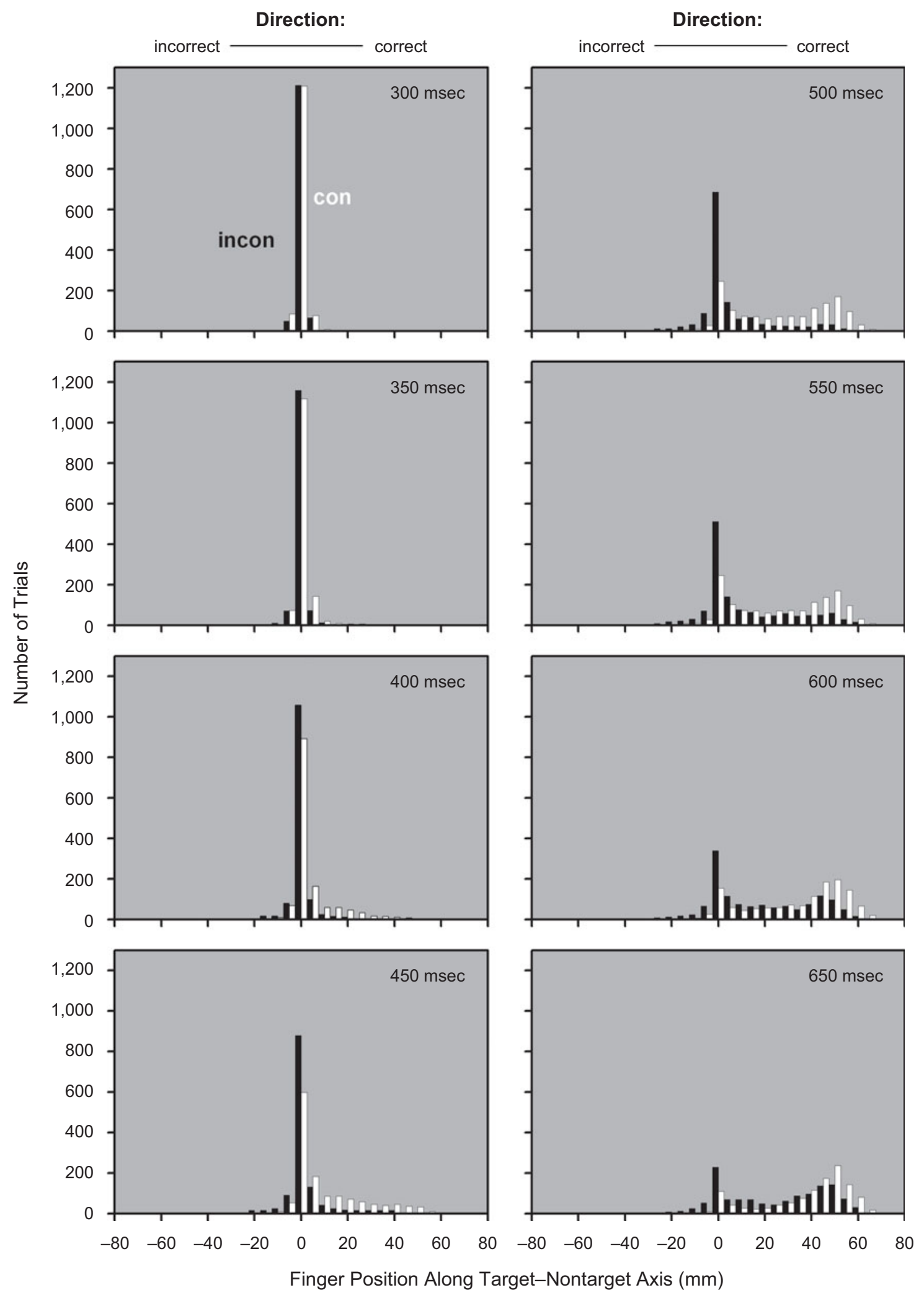

Figure 7. Spatial distributions of finger positions in Experiment 2 (cuing interval 500 msec, prime-target SOA $100 \mathrm{msec})$. Conventions are the same as in Figure 3. 


\section{A}

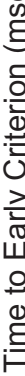

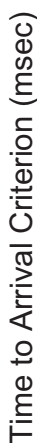

\section{B}

\section{Cuing Interval:}

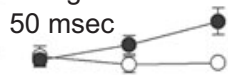

600

500

400

300
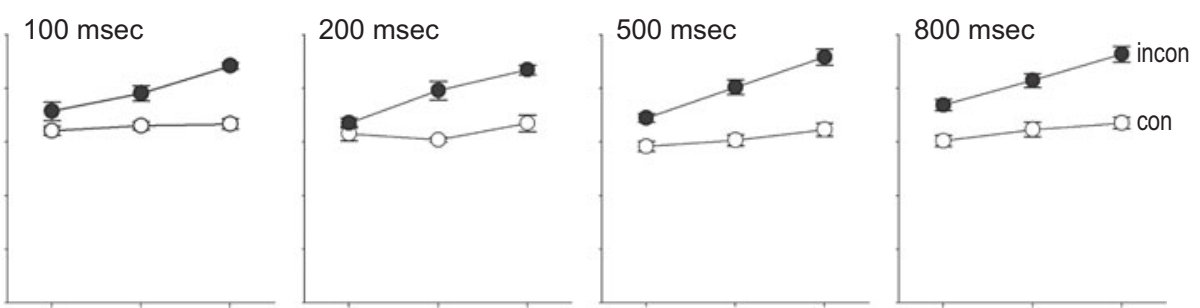
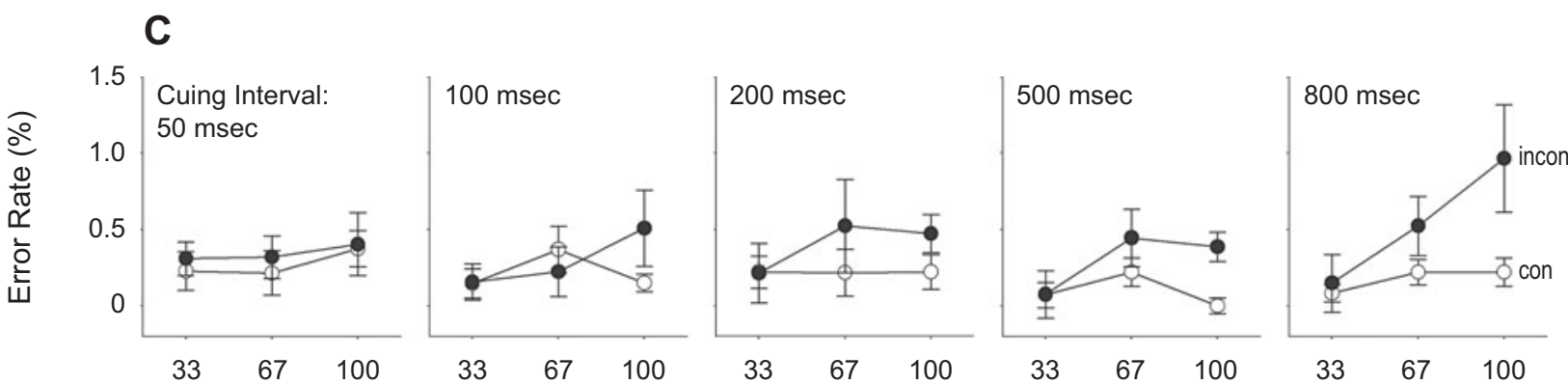

Prime-Target SOA (msec)

Figure 8. Parameters of pointing trajectories in Experiment 2 as a function of prime-target SOA. Conventions are the same as in Figure 4.

val $\left[F_{1}(4,28)=14.00, p<.001\right]$, whereas prime-target SOA had no influence on the onset times (Figure 9A). If priming onset was indeed locked to prime onset, a regression of priming onset on target onset should yield a slope of -1 . Again, priming onsets depended linearly on target onset, but the slopes were more variable than in Experiment 1 and not always statistically significant. Slopes ranged from -0.48 to $-1.22,2.03 \leq F(1,22) \leq$ $6.72, .017 \leq p \leq .169, .82 \leq R^{2} \leq .94$, and were not significantly different from the slope of -1 that would be predicted if onsets were in fact time-locked to the primes (all $p \mathrm{~s} \geq .123$ ). Peak amplitudes of the trajectorial priming functions were significantly different from zero $\left[F_{\text {intercept }}(1,7)=227.81, p<.001\right]$ at all prime-target SOAs [all $F_{\mathrm{s}}(1,7) \geq 74.30$, all $\left.p \mathrm{~s}<.001\right]$. They increased strongly with increases in prime-target SOA $\left[F_{\mathrm{S}}(2,14)=\right.$ $53.89, p<.001]$ and cuing interval $\left[F_{1}(4,28)=21.24\right.$, $p<.001]$. The interaction effect did not reach significance (Figure 9B). In sum, our data indicate that the more efficiently attention was directed to a certain shape, the more it enhanced visuomotor processing of upcoming stimuli of that shape, thereby amplifying the effects of the respective primes.

Prime ID. Participants' ability to indicate the position of the red prime in the cued shape was essentially at chance (Figure 10, right panels). Out of the $120 \chi^{2}$ tests (on crosstables of hits, false alarms, misses, and correct rejections) that were conducted for each participant, cuing interval, and prime-target SOA, only 3 came out significant, ${ }^{6} 2$ of them with participants scoring below chance. Because all three significant results stem from different participants in different conditions, it is likely that no systematic identifications of prime stimuli underlie these results. As in Experiment 1, visual awareness of the primes was thus 
A

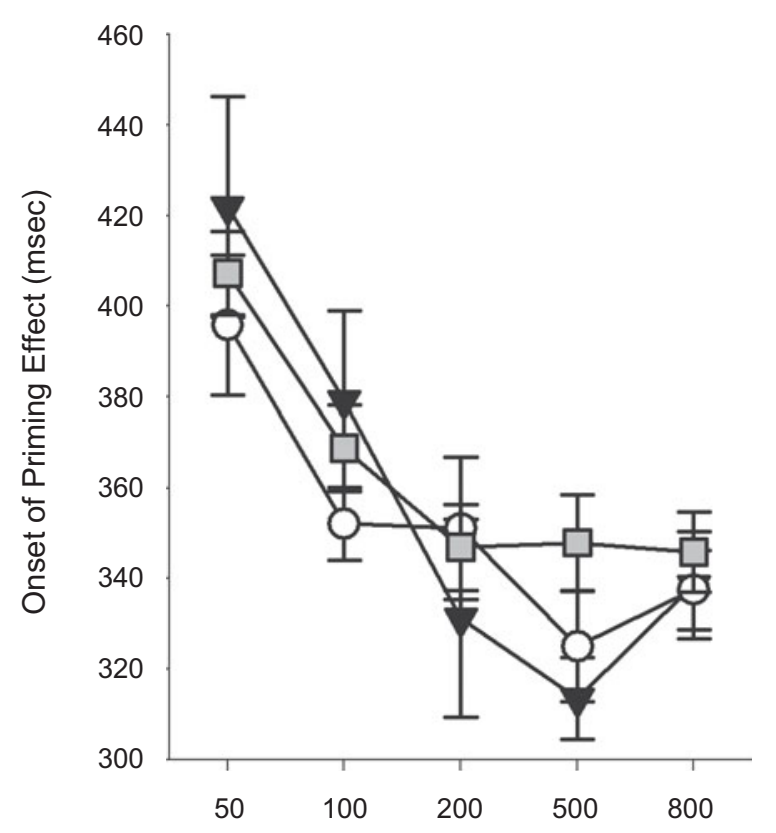

B

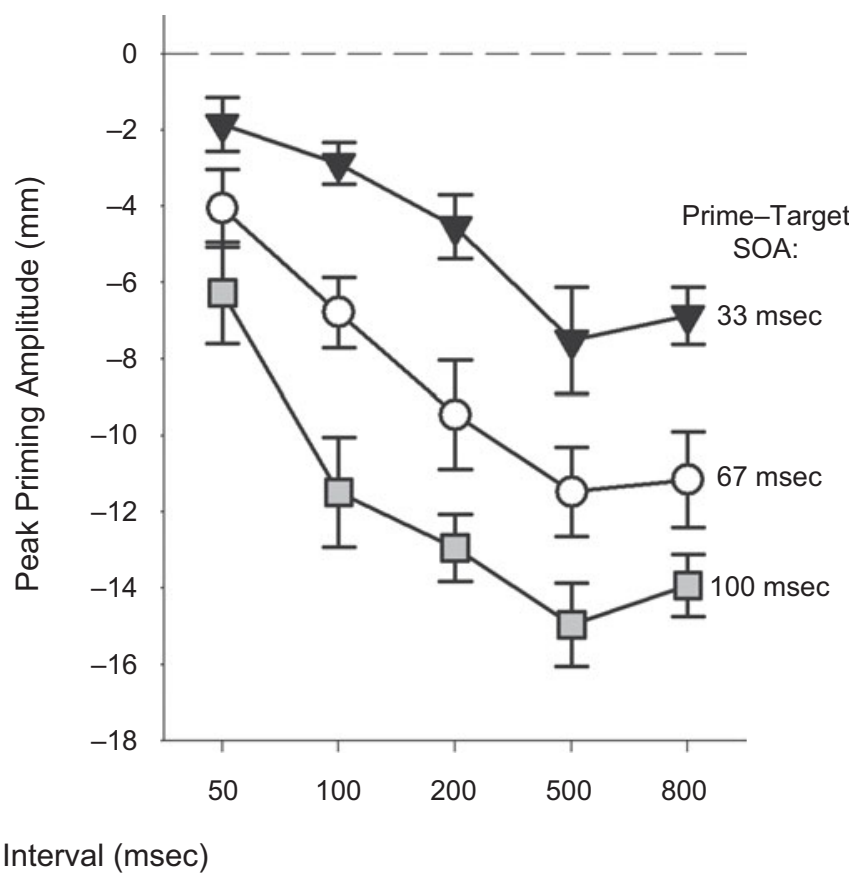

Figure 9. Parameters of priming trajectories in Experiment 2 as a function of cuing interval. Conventions are the same as in Figure 5.

dissociated from both response priming and attentional selection of the primes.

\section{GENERAL DISCUSSION}

Our results show that feature-based attention modulates the visuomotor processes underlying response priming. Feature-based attentional enhancement of response priming is similar to the effects of space-based attention (Schmidt \& Seydell, 2008) and to those obtained by manipulating color contrast directly (Schmidt et al., 2006), consistent with the idea that attention enhances effective stimulus contrast (Carrasco, Ling, \& Read, 2004; Reynolds \& Chelazzi, 2004; Sumner et al., 2006; Treue \& Martínez-Trujillo, 1999). That feature-based attentional selection has taken place can be inferred directly from the time course of primed pointing movements in inconsistent trials, especially in Experiment 1 . Because all primes are arranged evenly around the starting position of the finger, prior to attentional selection they could only exert a spatially neutral influence on the pointing trajectory. It is only by feature-based selection of a particular prime pair that the priming effect becomes spatially selective, with only one of the primes (the circle-shaped one in Experiment 1, the red one in Experiment 2) drawing the finger into a specific direction. Therefore, attentional selection is a prerequisite for performing the task at all and for obtaining spatially directed priming effects (Schmidt \& Seydell, 2008). In turn, our observation of spatially directed priming effects (detours in prime direction and full-fledged response errors to the misleading prime) implies that feature-based selection of the response-relevant positions must have taken place.
Although this argument holds nicely for Experiment 1, where many detours and errors were observed, we have to be a bit more cautious about Experiment 2, where detours and errors were rare and priming effects manifested in delayed response onsets only. The absence of overt detours may indicate that cuing on the basis of shape is generally less efficient than cuing on the basis of color. However, it may also be due to unspecific differences in task difficulty, which was not equated across our experiments: Selection by color might be faster than selection by shape, and it might be more difficult to select among shapes that share some feature elements (cf. Bichot, Rossi, \& Desimone, 2005; Theeuwes, 1991). Whatever the reason for the slower responses in Experiment 2, we would expect them to decrease the likelihood of overt detours, which mainly occur in trials with fast pointing onset (Figures 3 and 7; Schmidt et al., 2006). On the other hand, the fact that priming effects are still clearly time-locked to prime instead of target onset suggests that the underlying response conflicts are similar in responses with delayed onsets and those with overt detours, so that our conclusions from Experiment 1 will probably also hold for Experiment 2 .

In both experiments, large response priming effects were observed even though prime stimuli were (for all practical purposes) unidentifiable to the participants. Many studies have shown that primes in response priming tasks rapidly trigger the specific motor responses assigned to them. This was first demonstrated in lateralized readiness potentials in the EEG (Dehaene et al., 1998; Eimer \& Schlaghecken, 1998, 2003; Jaśkowski, van der Lubbe, Schlotterbeck, \& Verleger, 2002; Leuthold \& Kopp, 1998; Vath \& Schmidt, 2007). Moreover, analyses of primed pointing responses 


\section{Prime ID (Proportion Correct)}

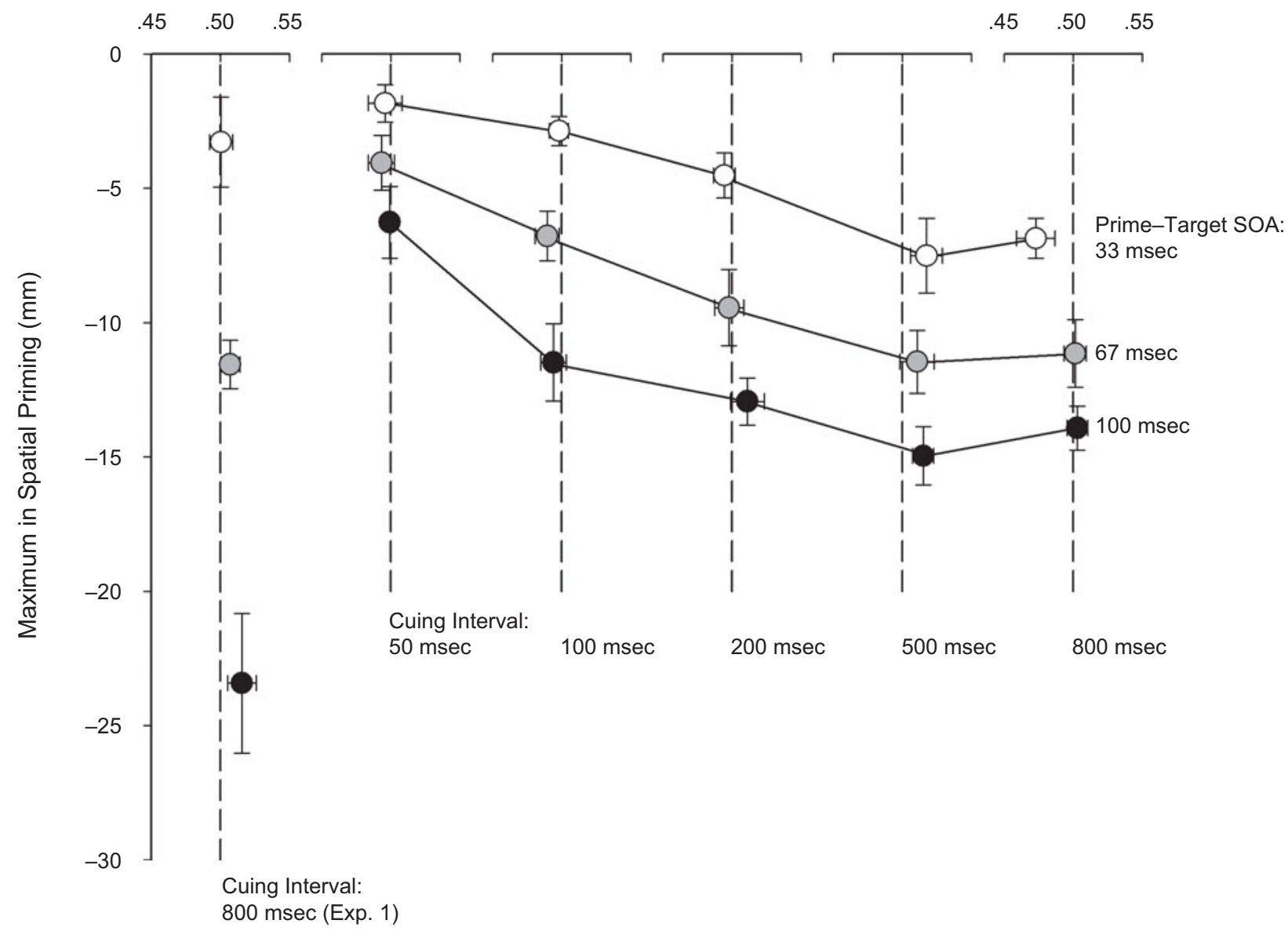

Figure 10. Each panel plots the maximum of the spatial priming effect against prime identification accuracy. Left panel: Experiment 1, where prime identification accuracy was measured only for the longest cuing interval. Right panels: Data from all five cuing intervals in Experiment 2. Bidirectional error bars denote standard errors of the mean corrected for between-subjects variance (Bakeman \& McArthur, 1996; Loftus \& Masson, 1994). All panels are scaled equally.

indicate that the earliest phases of the priming effect depend only on prime but not on target characteristics, and that they are independent of visual awareness of the prime (Mattler, 2003; Schmidt et al., 2006; Schmidt \& Schmidt, 2009; Vath \& Schmidt, 2007; Vorberg et al., 2003). The rapid-chase theory of response priming (Schmidt et al., 2006; Schmidt \& Schmidt, 2009; Vath \& Schmidt, 2007) therefore proposes that response priming is based on sequential, nonoverlapping waves of rapid feedforward activation (feedforward sweeps; see Lamme \& Roelfsema, 2000; see also Bullier, 2001; Thorpe, Fize, \& Marlot, 1996; VanRullen \& Thorpe, 2002), which are elicited in turn by primes and targets and traverse the visuomotor system in strict sequence, directly triggering the assigned responses (Neumann, 1990). Feedforward activation by the primes would still be largely free of feedback information; it would thus outrun the recurrent processing often assumed necessary for generating visual awareness of the primes (Di Lollo, Enns, \& Rensink, 2000; Fahrenfort, Scholte, \& Lamme, 2007; Lamme \& Roelfsema, 2000), and escape subsequent degradation by visual backward masking. This idea would explain the consistent finding that response priming remains unharmed by visual masking of the primes (Mattler, 2003; Schmidt, 2002; Schmidt \& Vorberg, 2006; Vorberg et al., 2003).

Our results indicate that attention and awareness are indeed different processes (Lamme, 2003, 2005): Clearly, successful attentional selection is not a sufficient condition for visual awareness of the selected stimuli. Indeed, our results demonstrate two types of dissociation: between response priming and visual awareness of the primes, and between visual awareness and feature-based attention. Rapid-chase theory can explain this dissociation by suggesting that attentional selection based on color or shape, just like selection based on spatial cues, enhances the processing dynamics of upcoming stimuli in feature space (Schmidt \& Seydell, 2008; Sumner et al., 2006). This enhancement takes place before the occurrence of prime and target stimuli and is an integral part of the feedforward processes they elicit, without necessarily affecting the recurrent processes that lead to visual awareness. This way, feature-based attention can modulate the dynamics 
of visuomotor processing, even though the primes consistently remain outside awareness.

\section{AUTHOR NOTE}

Experiments were conducted at the University of Giessen, Germany. We thank Karl R. Gegenfurtner, Anna Seydell, Valerie Hauch, Katharina Osswald, and Lena Vorobyova. This research was supported by Grant Schm1671/1-4 from the German Research Foundation to T.S. Correspondence concerning this article should be addressed to F. Schmidt, University of Kaiserslautern, Faculty of Social Sciences, Psychology I, Erwin-Schrödinger-Str. Geb. 57, D-67663 Kaiserslautern, Germany (e-mail: filipp.schmidt@sowi.uni-kl.de).

\section{REFERENCES}

Allport, [D.] A. (1989). Visual attention. In M. I. Posner (Ed.), Foundations of cognitive science (pp. 631-682). Cambridge, MA: MIT Press.

Bakeman, R., \& McArthur, D. (1996). Picturing repeated measures: Comments on Loftus, Morrison, and others. Behavior Research Methods, Instruments, \& Computers, 28, 584-589.

Bichot, N. P., Rossi, A. F., \& Desimone, R. (2005). Parallel and serial neural mechanisms for visual search in macaque area V4. Science, 308, 529-534. doi:10.1126/science. 1109676

BreitMeYer, B. G., \& ÖĞMEN, H. (2006). Visual masking: Time slices through conscious and unconscious vision. New York: Oxford University Press.

BULLIER, J. (2001). Integrated model of visual processing. Brain Research Reviews, 36, 96-107. doi:10.1016/S0165-0173(01)00085-6

Carrasco, M., Ling, S., \& Read, S. (2004). Attention alters appearance. Nature Neuroscience, 7, 308-313. doi:10.1038/nn1194

Corbetta, M., Miezin, F. M., Dobmeyer, S., Shulman, G. L., \& PeTERSEN, S. E. (1990). Attentional modulation of neural processing of shape, color, and velocity in humans. Science, 248, 1556-1559. doi:10.1126/science. 2360050

Dehaene, S., Changeux, J.-P., Naccache, L., Sackur, J., \& SerGENT, C. (2006). Conscious, preconscious, and subliminal processing: A testable taxonomy. Trends in Cognitive Sciences, 10, 204-211. doi: 10.1016/j.tics.2006.03.007

Dehaene, S., Naccache, L., Le Clec'H, G., Koechlin, E., MuelLER, M., DehaENe-Lambertz, G., ET AL. (1998). Imaging unconscious semantic priming. Nature, 395, 597-600. doi:10.1038/26967

Di Lollo, V., EnNS, J. T., \& Rensink, R. A. (2000). Competition for consciousness among visual events: The psychophysics of reentrant visual processes. Journal of Experimental Psychology: General, 129, 481-507. doi:10.1037/0096-3445.129.4.481

Eimer, M., \& SCHLAGHeCKEN, F. (1998). Effects of masked stimuli on motor activation: Behavioral and electrophysiological evidence. Journal of Experimental Psychology: Human Perception \& Performance, 24, 1737-1747. doi:10.1037/0096-1523.24.6.1737

Eimer, M., \& SchlaghecKen, F. (2003). Response facilitation and inhibition in subliminal priming. Biological Psychology, 64, 7-26.

Fahrenfort, J. J., Scholte, H. S., \& Lamme, V. A. F. (2007). Masking disrupts reentrant processing in human visual cortex. Journal of Cognitive Neuroscience, 19, 1488-1497. doi:10.1162/jocn.2007.19.9.1488

JAMES, W. (1890). The principles of psychology. New York: Holt.

Jaśkowski, P., van der Lubbe, R. H. J., Schlotterbeck, E., \& VerLEGER, R. (2002). Traces left on visual selective attention by stimuli that are not consciously identified. Psychological Science, 13, 48-54.

Kanai, R., Tsuchiya, N., \& Verstraten, F. A. J. (2006). The scope and limits of top-down attention in unconscious visual processing. Current Biology, 16, 2332-2336. doi:10.1016/j.cub.2006.10.001

Kentridge, R. W., Nijboer, T. C. W., \& Heywood, C. A. (2008). Attended but unseen: Visual attention is not sufficient for visual awareness. Neuropsychologia, 46, 864-869. doi:10.1016/j.neuropsychologia.2007.11.036

Koch, C., \& TsuchiYa, N. (2007). Attention and consciousness: Two distinct brain processes. Trends in Cognitive Sciences, 11, 16-22. doi:10.1016/j.tics.2006.10.012

LAMme, V. A. F. (2003). Why visual awareness and attention are different. Trends in Cognitive Sciences, 7, 12-18.

Lamme, V. A. F. (2005). The difference between visual attention and awareness: A cognitive neuroscience perspective. In L. Itti, G. Rees,
\& J. K. Tsotsos (Eds.), Neurobiology of attention (pp. 167-174). San Diego: Elsevier Academic Press.

Lamme, V. A. F., \& Roelfsema, P. R. (2000). The distinct modes of vision offered by feedforward and recurrent processing. Trends in Neurosciences, 23, 571-579.

Leuthold, H., \& KopP, B. (1998). Mechanisms of priming by masked stimuli: Inferences from event-related brain potentials. Psychological Science, 9, 263-269.

LofTus, G. R., \& MASsON, M. E. J. (1994). Using confidence intervals in within-subject designs. Psychonomic Bulletin \& Review, 1, 476-490.

Macmillan, N. A., \& Creelman, C. D. (2005). Detection theory: A user's guide (2nd ed.). Mahwah, NJ: Erlbaum.

Martínez-Trujillo, J. C., \& Treue, S. (2004). Feature-based attention increases the selectivity of population responses in primate visual cortex. Current Biology, 14, 744-751. doi:10.1016/j.cub.2004.04.028

MattLer, U. (2003). Priming of mental operations by masked stimuli. Perception \& Psychophysics, 65, 167-187.

Maunsell, J. H. R., \& Treue, S. (2006). Feature-based attention in visual cortex. Trends in Neurosciences, 29, 317-322. doi:10.1016/j.tins .2006 .04 .001

McMains, S. A., \& Somers, D. C. (2004). Multiple spotlights of attentional selection in human visual cortex. Neuron, 42, 677-686. doi:10 1016/S0896-6273(04)00263-6

Melcher, D., Papathomas, T. V., \& Vidnyánszky, Z. (2005). Implicit attentional selection of bound visual features. Neuron, 46, 723-729. doi:10.1016/j.neuron.2005.04.023

MerikLe, P. M., \& Joordens, S. (1997). Parallels between perception without attention and perception without awareness. Consciousness \& Cognition, 6, 219-236. doi:10.1006/ccog.1997.0310

MounTs, J. R. W., \& Melara, R. D. (1999). Attentional selection of objects or features: Evidence from a modified search task. Perception \& Psychophysics, 61, 322-341.

Neumann, O. (1990). Direct parameter specification and the concept of perception. Psychological Research, 52, 207-215.

Neumann, O., \& KLOTZ, W. (1994). Motor responses to nonreportable, masked stimuli: Where is the limit of direct parameter specification? In C. Umiltà \& M. Moscovitch (Eds.), Attention and performance $X V$ : Conscious and nonconscious information processing (pp. 123-150). Cambridge, MA: MIT Press.

O'Craven, K. M., Rosen, B. R., Kwong, K. K., Treisman, A., \& SAVOY, R. L. (1997). Voluntary attention modulates fMRI activity in human MT-MST. Neuron, 18, 591-598. doi:10.1016/S0896 $-6273(00) 80300-1$

O'Regan, J. K., \& NoË, A. (2001). A sensorimotor account of vision and visual consciousness. Behavioral \& Brain Sciences, 24, 939-1031. doi:10.1017/S0140525X01000115

Posner, M. I. (1994). Attention: The mechanisms of consciousness. Proceedings of the National Academy of Sciences, 91, 7398-7403.

Reynolds, J. H., \& Chelazzi, L. (2004). Attentional modulation of visual processing. Annual Review of Neuroscience, 27, 611-647. doi:10.1146/annurev.neuro.26.041002.131039

SÀEnz, M., Buracas, G. T., \& Boynton, G. M. (2002). Global effects of feature-based attention in human visual cortex. Nature Neuroscience, 5, 631-632. doi:10.1038/nn876

SÀenz, M., Buracas, G. T., \& Boynton, G. M. (2003). Global featurebased attention for motion and color. Vision Research, 43, 629-637. doi:10.1016/S0042-6989(02)00595-3

Schmidt, T. (2002). The finger in flight: Real-time motor control by visually masked color stimuli. Psychological Science, 13, 112-118. doi:10.1111/1467-9280.00421

Schmidt, T., Niehaus, S., \& Nagel, A. (2006). Primes and targets in rapid chases: Tracing sequential waves of motor activation. Behavioral Neuroscience, 120, 1005-1016.

Schmidt, T., \& Schmidt, F. (2009). Processing of natural images is feedforward: A simple behavioral test. Attention, Perception, \& Psychophysics, 71, 594-606. doi:10.3758/APP.71.3.594

Schmidt, T., \& Seydell, A. (2008). Visual attention amplifies response priming of pointing movements to color targets. Perception \& Psychophysics, 70, 443-455. doi:10.3758/PP.70.3.443

Schmidt, T., \& Vorberg, D. (2006). Criteria for unconscious cognition: Three types of dissociation. Perception \& Psychophysics, 68, 489-504.

Serences, J. T., \& Boynton, G. M. (2007). Feature-based attentional 
modulations in the absence of direct visual stimulation. Neuron, 55, 301-312. doi:10.1016/j.neuron.2007.06.015

Shin, K., Stolte, M., \& Chong, S. C. (2009). The effect of spatial attention on invisible stimuli. Attention, Perception, \& Psychophysics, 71, 1507-1513. doi:10.3758/APP.71.7.1507

Sumner, P., Tsai, P.-C., Yu, K., \& Nachev, P. (2006). Attentional modulation of sensorimotor processes in the absence of perceptual awareness. Proceedings of the National Academy of Sciences, 103, 1052010525. doi:10.1073/pnas.0601974103

Tapia, E., Breitmeyer, B. G., \& Shooner, C. R. (2010). Role of taskdirected attention in nonconscious and conscious response priming by form and color. Journal of Experimental Psychology: Human Perception \& Performance, 36, 74-87. doi:10.1037/a0017166

Theeuwes, J. (1991). Cross-dimensional perceptual selectivity. Perception \& Psychophysics, 50, 184-193.

Thorpe, S. J., Fize, D., \& Marlot, C. (1996). Speed of processing in the human visual system. Nature, 381, 520-522. doi:10.1038/381520a0

Treue, S., \& Martínez-Trujillo, J. C. (1999). Feature-based attention influences motion processing gain in macaque visual cortex. Nature, 399, 575-579.

Ulrich, R., \& Miller, J. (2001). Using the jackknife-based scoring method for measuring LRP onset effects in factorial designs. Psychophysiology, 38, 816-827. doi:10.1017/S0048577201000610

VAnRullen, R., \& Thorpe, S. J. (2002). Surfing a spike wave down the ventral stream. Vision Research, 42, 2593-2615. doi:10.1016/S0042 $-6989(02) 00298-5$

VAth, N., \& Schmidt, T. (2007). Tracing sequential waves of rapid visuomotor activation in lateralized readiness potentials. Neuroscience, 145, 197-208. doi:10.1016/j.neuroscience.2006.11.044

Vorberg, D., Mattler, U., Heinecke, A., Schmidt, T., \& SchwarzBACH, J. (2003). Different time courses for visual perception and action priming. Proceedings of the National Academy of Sciences, 100, 6275-6280. doi:10.1073/pnas.0931489100

ZHAOPING, L. (2008). Attention capture by eye of origin singletons even without awareness: A hallmark of a bottom-up saliency map in the primary visual cortex. Journal of Vision, 8, 1-18. doi:10.1167/8.5.1

\section{NOTES}

1. In other words, feature-based selection of the relevant prime feature enables spatial selection of the relevant prime locations. We take no stand on whether or not the spatial component requires splitting the focus of attention (McMains \& Somers, 2004).

2. Because the correct and the opposite targets and primes always lie in different halves of the display, this task is tantamount to indicating which one of the response-relevant positions contained the circle-shaped prime. In this regard, the task is comparable to the pointing task used in Experiment 2.

3. Pointing trajectories of the $n$ participants were averaged across each subsample of $(n-1)$ participants, excluding a different participant from each subsample. Movement parameters were estimated from each subsample, then averaged. This procedure allows for estimates that are much more reliable than those from single participants, without altering the average trajectories (Ulrich \& Miller, 2001).

4. The early criterion was chosen from inspection of the starting point distributions to avoid misjudging spurious deviations from the starting point as response onsets. Similarly, the arrival criterion was chosen from inspection of the spatiotemporal distribution of movement endpoints. Note that the early criterion is not strictly a criterion of movement onset, because in many trials the criterion was crossed only after a detour into the negative, nontarget direction. Nevertheless, a positive criterion had to be chosen because detours were small or absent in some conditions.

5. $\chi^{2}$ tests were based on 600 observations per participant and condition. They had a power of .69 for discriminating a performance level of $55 \%$ correct responses (effect size $w=.1$ ) at $\alpha=.05$.

6. $\chi^{2}$ tests were based on 120 observations per participant and condition. They had a power of .19 for discriminating a performance level of $55 \%$ correct responses (effect size $w=.1$ ) at $\alpha=.05$.

(Manuscript received November 18, 2009; revision accepted for publication March 28, 2010.) 